\title{
Anti-Hyperglycemic Activity of Phyllanthus emblica Leaves and Bark in Alloxan-Induced Diabetic Rats
}

Maria Ulfah, Novi I. Fauzi, Nela Simanjuntak, Anastasia Sinuraya

Indonesian School of Pharmacy, Bandung, West Java, Indonesia

\begin{abstract}
Phyllanthus emblica is empirically used to treat various diseases. Chemical compounds in this plant includes benzene derivatives, diterpen and monoterpen, furanolacton, flavonoids and sterols. The purpose of this research is to investigate anti-hyperglycemic activity of $P$. emblica. The diabetic animal model was obtained by administration of alloxan $120 \mathrm{mg} / \mathrm{kg}$ $\mathrm{BW}$ intraperitonial. The rats were divided into 9 groups, i.e., normal group, negative control ( $1 \% \mathrm{CMC}$ ), positive control (glibenclamide $0.5 \mathrm{mg} / \mathrm{kg} \mathrm{BW}$ ) and P. emblica leaves and bark ethanol extract at the dose of 500,750, and $1000 \mathrm{mg} / \mathrm{kg} \mathrm{BW}$. Determination of flavonoid content was performed through colorimetric method using UV-Vis spectrophotometer at 425 $\mathrm{nm}$. After 7 days of induction, the entire group was treated for 21 days, fasting blood glucose was performed on days $0,1,8,15$ and 22 . Then the data of fasting blood glucose level in mice was treated with one way ANOVA analysis and advanced test with post hoc Least Significant Differences (LSD) method. The percentage of the blood glucose decrease from the animal treated with leaves extract at doses of 500,750 and $1000 \mathrm{mg} / \mathrm{kg} \mathrm{BW}$, respectively, were $22.47 \% ; 21.03 \%$; and $24.52 \%$, while those of bark extract were $32.19 \% ; 31.61 \%$; and $37.24 \%$, respectively. Determination of total flavonoid level showed that the highest amount of flavonoids was observed in leaves (35.838 mg/g Quercetin). In conclusion, P. emblica bark and leaves showed anti-hyperglycemic activity.
\end{abstract}

Key words: anti-hyperglycemic, alloxan, Phyllanthus emblica, Wistar

\section{Introduction}

One of the traditional remedies used for diabetes mellitus is $P$. emblica. It is a native Indian plant. In Indonesia this plant is called Mala$k a$. All parts of the plant have potential to be used for medicinal purpose. This potential is influenced by the biodiversity of the secondary metabolites in the plant. The secondary metabolites compounds contained in this plant include benzene and monoterpenes, furanolactone, flavonoids and sterols. ${ }^{1}$ The presence of certain secondar metabolite is usually similar in the same plant, nevertheless the level varies between one part of the plant with others. $^{2}$

Flavonoid compounds have recently attracted researchers to examine its biological activities, including anti-hyperglycemic activity. The potential effect of flavonoid as anti-diabetes is mainly through the modulation effect

Corresponding author: Maria Ulfah. Indonesian School of Pharmacy, Bandung, West Java, Indonesia.

Email: maria.ulfah@stfi.ac.id.

Received: 24 June 2019. Revised: 15 July 2019 Published: 30 August 2019. 
of glucose transporter by increasing GLUT-2 expression in pancreatic $\beta$ cells and increasing expression and promoting GLUT-4 translocation through $\mathrm{PI} 3 \mathrm{~K} / \mathrm{AKT}, \mathrm{CAP} / \mathrm{Cb} 1 / \mathrm{TC} 10$ and AMPK pathways. Assessment of recent findings on the beneficial effects of flavonoids on the management of diabetes focus in exploring the role of flavanoid compounds in modulating glucose transporter proteins at the cellular and molecular levels. ${ }^{3,4}$

The hyperglycemic activity of $P$. emblica has been reported by Shamim et al where $P$. emblica fruit extract at a dose of $200 \mathrm{mg} / \mathrm{kg}$ BW was reported to significantly decrease blood sugar levels in alloxan-induced mice. A decrease in blood glucose level similar to that of chlorpamamide at doses of $84 \mathrm{mg} / \mathrm{kg}$ $\mathrm{BW}^{5-8}$ Nevertheless, there is limited information on anti-hyperglycemic activity of other part of this plant, such as seeds, leaves, bark, and roots. Flavonoids content in the part of the plant may also influence its biological activies. Therefore, this study was conducted to investigate the effect of flavonoids in leaves and bark ethanolic extract of $P$. emblica on anti-hyperglycemic activity in alloxan-induced diabetic rats.

\section{Methods}

\section{Materials}

The materials used in this study included leaves and bark of $P$. emblica obtained from Jelekong Village, Bandung, glibenclamide (Sigma-Adlich), alloxan (Sigma-Aldrich), quercetin (Sigma Aldrich), methanol, car- boxyl methyl cellulose (CMC), 96\% ethanol, aluminum chloride $\left(\mathrm{AlCl}_{3}\right)$, sodium acetate, destilled water, and materials for testing simplicia parameters

\section{Plant determination}

Plant determination was conducted at Herbarium Jatinangor Laboratory of Plant Taxonomy Department of Biological Science of Universitas Padjadjaran and School of Life Science Technology (SITH) Institute Technologi Bandung.

\section{Animal Model}

Male Wistar rats (2-3 months old, 150-250 g) were used in this study. Rats were provided by Animal Laboratory of The Wistar, Bandung and kept under usual management condition in this institution. All conducted methods have followed the standard of management care for laboratory animals.

\section{Extraction}

Leaves and bark of $P$. emblica were dried and ground. $P$. emblica leaf extract was made by maceration method. Three hundred and fifty grams of leaves powder was macerated in $9600 \mathrm{ml}$ of ethanol $96 \%$ for 18 hours, with occasional stirring, The extract was evaporated with a low pressure vaporizer to obtain a thickened extract. $P$. emblica bark extract was made through soxhlet method. The powder was wrapped with filter paper and heated with $1800 \mathrm{ml}$ ethanol. The extract was thickened using rotary evaporator.

Table 1. Extraction of $P$. emblica Leaves and Bark

\begin{tabular}{cccc}
\hline Part & Amount & Thickened Extract & Yield Extract \\
\hline Leaves & $700 \mathrm{~g}$ & $288.36 \mathrm{~g}$ & $41.19 \%$ \\
Bark & $940 \mathrm{~g}$ & $200 \mathrm{~g}$ & $21.27 \%$ \\
\hline
\end{tabular}


Table 2. Phytochemical Screening of $P$. emblica

\begin{tabular}{lcccc}
\hline \multirow{2}{*}{ Secondary metabolites } & \multicolumn{2}{c}{ Leaves } & \multicolumn{2}{c}{ Bark } \\
\cline { 2 - 5 } & Raw & $\begin{array}{r}\text { Ethanol } \\
\text { Extract }\end{array}$ & Raw & Ethanol Extract \\
\hline Alkaloid & + & + & + & + \\
Flavonoid & + & + & + & + \\
Saponin & + & + & + & + \\
Tannin & + & + & + & + \\
Quinone & + & + & - & - \\
Monoterpenoid and Sesquiterpenoids & + & + & - & - \\
Steroid & - & - & - & - \\
Triterpenoid & - & - & - & - \\
\hline$+=$ presence, $-=$ absence & & & &
\end{tabular}

Determination of flavonoids

Phytochemical screening of leaves and bark extract were performed to examine the presence of alkaloids, steroids/triterpenoids, saponins, tannins, flavonoids, quinones, monoterpenoid, and sesquiterpenoids. Determination of flavonoid content was performed through colorimetric method using UV-Vis spectrophotometer at $425 \mathrm{~nm}$.

Quercetin spectrum with methanol yielded a wavelength of band I of $371 \mathrm{~nm}$, with the band II not being apparent. In addition of $\mathrm{AlCl}_{3}$ and $\mathrm{HCl}$ shift reagents there was a batochromic shift in band I of $53.5 \mathrm{~nm}$ with a wavelength of $424.5 \mathrm{~nm}$ which states that the compound has 5-OH, C-flavonoid ring. In the addition of the $\mathrm{NaOH}$ reagent there was a shift in band I of $65.5 \mathrm{~nm}$ with a wavelength of $436.5 \mathrm{~nm}$ which states that the compound has 4'-OH in the flavonoid B ring which is similar to flavonol/quercetin. The complex between quercetin with $\mathrm{AlCl}_{3}$ and sodium acetate $15 \mathrm{ppm}$ gives an absorbance of 1.682 and the maximum wavelength $(\lambda)$ at $425 \mathrm{~nm}$. The absorbance of the extract was measured using three repetitions.

\section{Antihyperglycemic assay}

Rats were acclimatized to the environment. All groups, except normal group was induced with alloxan intraperitonial with dose $120 \mathrm{mg} /$ $\mathrm{kg} \mathrm{BW}$, alloxan was dissolved in physiological $\mathrm{NaCl}$. Fasting blood glucose levels and body weight of rats were examined on days 0 , 3, 6 and 7. Fasting blood glucose levels were examined using glucosemeter. Blood sample was collected from tail. Rats are classified as diabetes if fasting blood glucose level $>140$ $\mathrm{mg} / \mathrm{dl}$.

Table 3. Total Flavonoid in P. emblica Extract

\begin{tabular}{cc}
\hline Ethanol Extract & Levels of Flavonoids (mg/g Quercetin) \\
\hline Leaf $1000 \mathrm{mg}$ & 35.838 \\
Leaf $750 \mathrm{mg}$ & 26.878 \\
Leaf $500 \mathrm{mg}$ & 17.919 \\
Bark $1000 \mathrm{mg}$ & 28.992 \\
Bark $750 \mathrm{mg}$ & 20.294 \\
Bark $500 \mathrm{mg}$ & 14.496 \\
\hline
\end{tabular}


Diabetic rats were divided into 9 groups and each group consisted of 5 rats. The treatment for 9 groups included normal group, negative control (1\% CMC), positive control (glibenclamide $0.5 \mathrm{mg} / \mathrm{kg} \mathrm{BW}$ ) and P. emblica leaves and bark ethanol extract at the dose of 500, 750, and $1000 \mathrm{mg} / \mathrm{kg} \mathrm{BW}$. Fasting defined as the rats were left 18 hours without food, only drink provided. Fasting blood glucose and body weight of rats were examined on days $0,1,8,15$, and 22 . One way ANOVA analysis and advanced test with post hoc Least Sinificant Differences (LSD) method were perffromed.

\section{Results and Discussion}

Plant determination results showed that the plant used in this study was $P$. emblica. The extract obtained were $288.36 \mathrm{~g}$ and $200 \mathrm{~g}$ for leaves and bark, respectively. The results of phytochemical screening showed that bark and leaves of P. emblica contained flavonoids, saponins, and tannins. This flavonoid compound is considered responsible in antihyperglyccemic activity of $P$. emblica. Determination of total flavonoid level showed that the highest amount of flavonoids was observed in leaves (35.838 mg/g Quercetin).
In this study, alloxan was used to induce diabetes. Alloxan is a pyrimidine derivative, with another name 2,4,5,6-tetraoxypirimidine; 2,4,5,6-pyrimonyron and 1,3-diazinan2,4,5,6-tetron; mesoxalylurea 5-oxobarbiturate acid. Pure alloxan is obtained from the oxidation of uric acid by nitric acid. Alloxan is an unstable, hydrophilic compound. The activity of this free radical compound increase the concentration of calcium cytosol that causes rapid destruction of pancreatic $\beta$ cells. Alloxan compounds also have specific cytotoxic properties in Langerhans $\beta$ cells and evoke radical groups that damage Langerhans $\beta$ cells due to increased free radicals in the body. ${ }^{9,10}$

Bark ethanol extract exhibited better activity compared to leaves extract. The percentage of the blood glucose decrease from the animal treated with leaves extract at doses of 500,750 and $1000 \mathrm{mg} / \mathrm{kg} \mathrm{BW}$, respectively, were $22.47 \% ; 21.03 \%$; and $24.52 \%$, while those of bark extract were $32,19 \% ; 31.61 \%$; and $37.24 \%$, respectively.

Based on one way ANOVA analysis, leaves and bark ethanol extract of $P$. emblica at doses of 500, 750 and $1000 \mathrm{mg} / \mathrm{kg} \mathrm{BW}$ exhib-

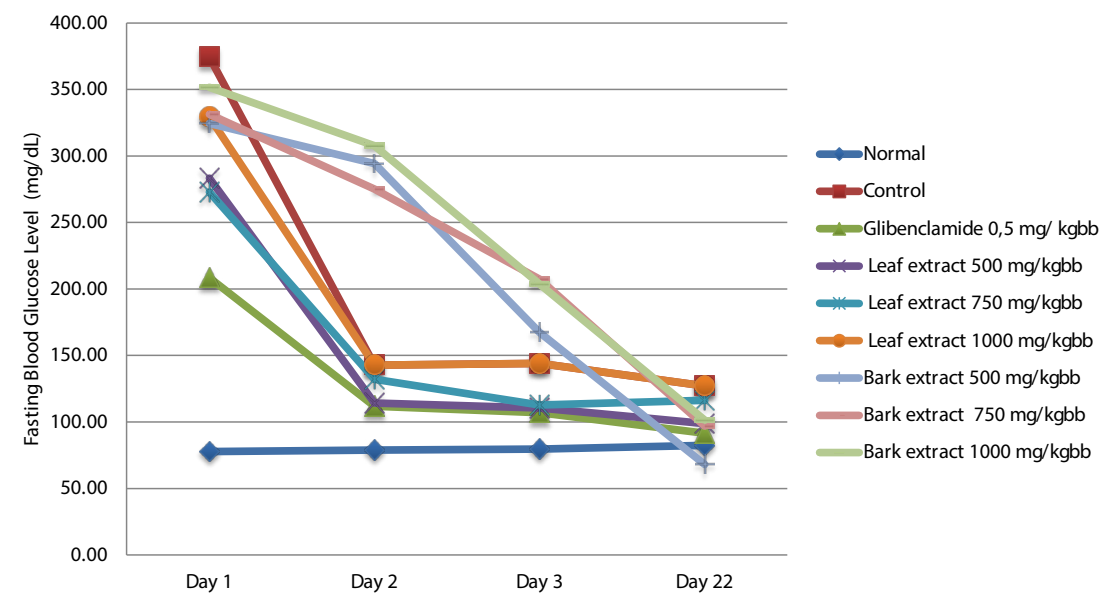

Figure 1. Fasting Bloof Glucose After Treatment 
ited antihyperglycemic effect with $\mathrm{P}<0.05$ at week 2-3.

Our study found that the greater level of flavonoids showed the greater anti-hyperglycemic activity. Flavonoids regulate glucose transporter protein in cells by increasing GLUT-2 expression in pancreatic $\beta$ cells. Beside, presence of C-2-C-3 double bond and C-4 ketonic group can improve $\alpha$-glucosidase activities that are are related with antidiabetic property. ${ }^{11-14}$

\section{Conclusion}

P. emblica bark and leaves showed antihyperglycemic activity.

\section{Acknowledgement}

The authors would like to thank Indonesian School of Pharmacy (STFI) and the Hazanah foundation for their support during the research.

\section{Funding}

None.

\section{Conflict of Interest}

None declared.

\section{References}

1. Baliga MS, Dsouza JJ. Amla (Emblica officinalis gaertn), a wonder berry in the treatment and prevention of cancer. Journal of Cancer Prevention. 2011;20(3): 225-239.

2. Dasaroju S, Gottimukkala KM. Current trend in the research of emblica officinalis (amla): A pharmacological perspective. International Journal Pharmaceutical Sciences. 2014;24(3):150-159.

3. Dhale DA. Pharmacognostic evaluation of Phyllantus emblica Linn (Euphorbiaceae). International Journal Pharma- ceutical Biomedical Sciences. 2012;3(3): 210-217.

4. Elobeid MA, Ahmed EA. Antidiabetic efficiacy of aqueous fruit extract of amla (Emblica officinalis, Gaertn) in streptozotocin-induced diabetes mellitus in male rats. Tropical Journal of Pharmaceutical Research. 2014;14(5): 801-806.

5. Hasan R, Islam N, Islam R. Phytochemistry, pharmacological activities and traditional uses of Emblica officinalis: A review. International Current Pharmaceutical Journal. 2016;5(2): 14-21.

6. Holthoon L. Phytochemistry, traditional uses and cancer chemopreventive activity of amla (Phyllanthus emblica). Journal of Applied Pharmaceutical Science. 2016;12(1): 388-389.

7. Hussain A, Marouf H. Flavonoid as alternatives in treatment of type 2 diabetes mellitus. Academia Journal of Medicinal Plants. 2013.1(2):31-36.

8. Krishnaveni M. Antidiabetic and antihyperlipidemic properties of Phyllanthus emblica Linn. (Euphorbiaceae) on streptozotocin induced diabetic rats. Pakistan Journal of Nutrition. 2010;9(1): 43-51

9. Vasant BS, Bhaskarrao DA, Bhanudas RS. Emblica officinalis: The wonder of ayurvedic medicine. World Journal of Pharmacy and Pharmaceutical Sciences. 2013;3(1): 285-306.

10. Srinivasan P, Vijayakumar S, Kothandaraman S, Palani M. Anti-diabetic activity of quercetin extracted from Phyllanthus emblica L. fruit: In silico and in vivo approaches. Journal of Pharmaceutical Analysis. 2018;8(2):109-118.

11. Ansari A, Shahriar MS, Hassan MM. Emblica officinalis improves glycemic status and oxidative stress in STZ induced type 2 diabetic model rats. Asian Pacific Journal of Tropical Medicine. 2014;7(1):21- 
25.

12. D'Souza JJ, D'Souza PP, Fazal F. Antidiabetic effects of the Indian indigenous fruit Emblica officinalis Gaertn: Active constituents and modes of action. Food \& Function. 2014;5(4):635-644.

13. Nampoothiri SV, Prathapan A, Cherian OL. In vitro antioxidant and inhibitory potential of Terminalia bellerica and Emblica officinalis fruits against LDL oxidation and key enzymes linked to type 2 diabetes. Food and Chemical Toxicology. 2011;49(1):125-131.

14. Sarian MN, Ahmed QU, Mat SZ. Antioxidant and antidiabetic effects of flavonoids: A structure-activity relationship based study. Biomed Research International. 2017;2017:8386065. 